\title{
Assessing Organizational Agility via Fuzzy Logic
}

\author{
Dr Nour-Mohammad Yaghoubi (Corresponding author) \\ Islamic Azad University, Zahedan Branch, Iran \\ E-mail: yaghoobinor@yahoo.com \\ Baqer Kord \\ Islamic Azad University, Zahedan Branch, Iran \\ Omolbanin Azadikhah \\ Master of Industrial Engineering, Islamic Azad University, Zahedan Branch, Iran
}

Received: February 15, 2011 Accepted: March 1, 2011 doi:10.5539/ibr.v4n3p135

\begin{abstract}
The only thing that doesn't change in the current revolutionary world is the change itself. Accessing to agility is required while dealing with efficient and useful reactions to changes and acquiring competitive advantages from the opportunities resulted from the change. Hence, at the beginning of this article, we have tried to propose the following subjects: the concept, importance and necessity of accessing agility and fuzz plus its reasons. Then, we will assess agility with the Goldman methodology based on fuzzy approach. In this respect, several questionnaires were distributed among the top managers of Saipa Yadak car co., Iran. Finally, after precise and through analyses, the sub- criteria were recognized based on the fuzzy approach and the possible obstacles for reaching the agility level and different recommendations were suggested.
\end{abstract}

Keywords: Agility, fuzzy, Virtual organization, Learning organization, Assessing agility, Agility levels, Fuzzyagility index

\section{Introduction}

Rapid changes in technology, globalization and privacy expectations are among the environmental features that most present organizations face with. In order to succeed in this environment, agility will create a competitive advantage which may be preserved by gaining fame through innovation and quality. Other organizations and firms as well as producers have to seek for agility in order to compete in $21^{\text {st }}$ century race since modern organizations are strained increasingly to find new and active ways in this globally dynamic market. Agility is able to improve capability of organizations in presenting their products and quality services and therefore, it turns into an important factor for presenting the effectiveness of the organization.

\section{Concept of Agility and Fuzzy}

The term "agility" was used for the first time by Iaccoca Agency in a report titled as "The Strategy of the Industrialized Specialist Agencies" in 1991 to describe the necessary capability for modern production. (Nagel \& Dove, 1991). The term "agile" explains the amount of quickness and responsiveness of an organization in dealing with its internal and external events. regarding the novelty of this concept, there is no commonly- accepted definition for agility, but Agarwal, Shankar \& Tiwari ( 2007) have summarized various definitions of agility in their review article.(see table 1)

Humans have challenged to gain unambiguous knowledge since many years ago. Since Aristotle introduced two -value logic till now, we have been able to reach remarkable achievements. Technology has progressed and has become more efficient. In early $20^{\text {th }}$ century, scientists came to this conclusion that the traditional structure of science is no longer able to describe new inventions. The problems that the Newton rules made in the molecular sizes interested the scientists and researchers in random phenomena and it finally led to development of statistics and probability. After using probability in probable mechanic, this theory was applied in other scientific branches as well. Unfortunately, in spite of partial success of probability theory in real subjects, it was not able to overcome the uncertainty in its general meaning. It was quite observable, especially in case of linguistic terms in colloquial language. These limits brought up a new theory about uncertainty which finally overcame ambiguity and unclear atmosphere in real scientific phenomena (Keler \& Boivan, 2002:8).

Fuzzy logic is a very important type of logic which was proposed by the Iranian professor, Mr. Lotfizadeh, in 1965 and seriously challenged Aristotle's binary logic. This logic not only is used in theoretical domain, but also it is applicable in industry and there are many researchers who are doing surveys on it. Fuzzy logic was at first 
introduced as a method for data processing which also defines the position of their membership and also the relation between them. Instead of processing 0 and 1, it just analyzes 0 to 1 ; i. e. a serious that has 2 members, $0 \& 1$, in Aristotle's logic, changes into a series with indefinite which possesses 0 to 1 . hence, fuzzy logic is closer to humans' behaviors and ways of thinking.

\section{Necessity of agility and usage of the fuzzy method}

In competitive markets, all businesses have to accept the changes. However, it needs to be noted that agility in business is not specified just to the companies; it is also vital for people. Today's business culture is unstable which is itself the consequence of technology and innovation. So, people should be willing to adapt themselves immediately with modern technologies and techniques, otherwise, they will not progress and will be substituted with mo capable people. Therefore, nowadays, agility is necessary for both individual and organizational levels. In today's tough and vague world, technological advancements and innovation is dependant on those people and organizations which can predict future before its arrival.

Fuzzy logic can solve the problems and it is able to be carried in both small and simple microcontroller systems and multi- channel computers, expended nets and controlling systems.

It can also be used in software, hardware or a combination of them. Fuzzy logic is a simple way to reach clear- cut results based on unclear and doubtful data. The metrology of this logic for controlling the systems follows the decision- making process in our brains and relies on the user's experiences to technical comprehension of the system.

\section{Fuzzy argument}

Fuzzy argument (which is also called "approximation") can create a fuzzy hypothesis from several hypotheses and as far as it is similar to human's argument, there is a great interest in fuzzy argument which constitutes the basis for fuzzy control, intelligent fuzzy systems and fuzzy decision- making process .

\section{1 usage of linguistic variables for numbers}

Prof. Lotfizadeh introduced linguistic variables in 1973, so it is better to consider words and linguistic topics for numbers. Knowledge, experience and thinking are operated as word in fuzzy system by computers. Then, the words are imaged and are entered to some ordinary numeral computers which are able to use the numbers. Note that the words are imaged by MFS.

\subsection{Application}

Theoretically, fuzzy logic was studied during the first quarter of the century and it was researched practically in the next 10 years, particularly by the Japanese congress .IFSA, in 1987. It deals with fuzzy logic more specifically than others, so Japan will be the leading country in developing fuzzy applications in industry. Misio Sogno did a lot of studies on the fuzzy controllers. Fuzzy logic is known as a useful method for classification and usage of data and it is approved that as far as it follows the human's controlling logic, it will remain the most excellent option to apply in most controlling systems. it can be used in micro- handy computers .

Its best advantage which has made it applicable in industrial development is its flexibility for data analyzing and decision- makings. In fact, fuzzy logic is a precise way of thinking in the most ambiguous and unclear affairs.

Since 1985, several attempts have been done for applying fuzzy theory in information management such as intelligent systems by universities and industries and great numbers of reports have been delivered on its usage in investment in stocks, trouble- shooting in different devices and medical diagnosis and most of them have used fuzzy theory in practice.

\section{Agility Organization}

Agility organization aims to please customers and employees. It is necessary for every organization to have some responsive capabilities for the recurring changes in its business circumstances.

Agile thinking in these organizations moves beyond conformity and tends to use potential opportunities in a turbulent environment and create a constant condition for its own innovations and capabilities.

Organizations need to establish agile organization for the following reasons:

- Short term business opportunities.

- Lack of all required organizational capabilities for immediate market presentation of a new product

- Unpredictability of constant changes in market levels; it is possible to distribute the risk between some cooperative companies through establishing a virtual organization.

- The key idea for establishing a virtual organization is to get benefit from immediate and short term market 
opportunities through incorporating the main capabilities of all separated agencies.

\subsection{Key Principles of Agile Organizations}

1 - To provide values to the customers

2- Importance of individuals and role of information

3- Inter/ intra cooperation in organization

4- Readiness for change

5.2 Organization's Agility Tools

Chart (figure 1) shows the organizational tools and agility enablers as organization, HR, technology and innovation.

1- Organizational structure: it needs to be flexible. Regarding the organization domain, below actions can be performed:

- Participation with other organizations

- Improvement in flexibility through decentralization and making flexible structures

- Focus on reconstruction and innovation

2- Individuals: capability and flexibility of personnel have key role in agile organizations which mostly confront permanent circumstances turbulences.

3- IT: one of the priorities of agile system is its high quantity of information. Also, the amount of exchanged information between coordinated organizations is very huge and it required the security of key information in the organization. Therefore, agile organizations need high- tech and flexible informational and communicational systems which can assure smooth and trustworthy transformation of information and conform to the unstable and unexpected conditions. In fact, information technology has been successful to overcome other technologies and industries in development and advancement and its different types have been used greatly along with modern information systems.

4- Innovation and creativity: every agile origination needs to deliver its solutions to the customers rather than selling its products to them. In fact, the ultimate goal in an agile productive organization is to provide an actual realization of order- making concept and to meet diverse and individual needs of each customer.

\section{Agility Capabilities}

Agility capabilities, as Sharifi \& Zhang (1999) have noted, include the capabilities which should be provided in an organization in order to create enough responsiveness for the changes.

- Responsiveness: ability to recognize changes and give responses to improve them immediately

- Competency: a great amount of abilities which prepares productiveness of activities in line with the organization's goals; in other words, capability of effective and efficient accessibility to the organization's targets and strategies.

- Quickness: capability to execute an operation in shortest time (Macauly, 1996)

\subsection{Improvements in Organization's Agile Capabilities}

In near future and in competitive periods in dynamic and progressive markets, organizations and companies need to establish and improve their agile capabilities and accept it as a priority in competition. One of the problems is concentration on agility improvement and also inflexibility of the pre- determined concepts of the organization. Here, agility is considered as en end- less way that can be the result of progressive improvement. Based on Ferdows \& Meyer's theories (1990), Vokurka and Fliedner (1998) designed a model for improving the agile capabilities. This chart suggests that those companies which focus on agile improvement, regardless of other capabilities, will probably face failure, so it is necessary to clarify and define competency in other competitive features and of course, it should be done before deciding to start and use agility. This sand- hill model which is somehow Ferdows \& Meyer's model suggests to firms and organizations to rely on agility for future competitions (Vokurka and Fliedner, 1998). (Figure2)

\section{Differences between traditional and agile organizations}

Ramesh and divid san believe to be traditional and agile differences.(Table2)

\section{New Organizational Types}

Each organization has 5 powers which are in conformity with each other and are influenced by the environmental factors. These five powers or elements which constitute the organization consist of structure, strategy, technology, personnel or their duties and managing procedures. 
Regarding the fact that virtual and learning organizations are really effective for agile organizations, some related information is mentioned in the following section:

\subsection{Virtual Organization}

One of the best examples of agile organizations is its virtual structure. Virtual organization is a new term in management terminology which describes a new shape and type of organization. Applying informational technologies such as internet, e- mail and great growth of computer usages has caused new organizational structures to enter the world with a quite different identity from large, traditional and bureaucracy organizations. The structures in these organizations are like small, independent and flexible units with advanced communicative systems.

The most important factors which determine virtual format in virtual organizations is dedicating activities to other organizations and supplying products and delivering services and coordinating with the units outside the organization. If the amount of these out sourcing is really great, it shows that the organization is moving faster towards virtual format.

\subsubsection{Different Types of Virtual Organizations}

Virtual organizations are divided into 4 main groups. Recently, the 3-D clover is also known as a type of virtual organizations.

- Modular organization: it arranges the un- strategic actions as a certain valuation and transfers them into external units, so that it can increase the prices and make powerful management.

- Network organization: it includes several cooperating units that posses similar strategic goals as parts of a net

- Unlimited organization: there is a correct relationship between external units, customers, producer, and other units, so that the organization does not determine a limit for external and internal parts. Also, there is no organizational limitation for this kind of organization.

- 3D clover organization: it is one the new organizational structures produced by Charles Handi. Its structure is similar to clover leaves that have 3 dimensions. (Jafarnejad and Shahaei,2006:5)

\section{Learning Organization}

The origin and etymology of learning organization dates back to 1920, but it s study as a remarkable subject belongs to the early 1980s. Learning organization is an organization that owns and manages all mental power, knowledge and experience of the organization for making changes and improving its conditions in a gradual manner. Learning organization has characteristics such as encouragement and applauding the personnel in all stages in order to increase regular learning from their works, possessing required systems and procedures for establishing learning and expanding it in the organization and considering value for organizational learning. From Peter Sang's point of view, learning methods in learning organization are as follows: individual skill, team learning, systematic thinking, common knowledge and conceptual models.

\section{Difference between traditional and learning organizations}

Learning organizations follow to teach and prepare their personnel to manage new changes. however learning needs to be active people and provide learning facilities, proper needs organizational structure, clear relationships, general knowledge and team work. There for it should be clear to determine ends and sources. which are created by learning organization for employer and employees .(Table3)

\section{Assessing Approaches and Models of Agility}

Several brilliant authors on agility (Goldman, Dave, Perris, Sharifi \& Gang, Yousef, Sarhadi, Gonaskaran, Toureng leen and others) have introduced different models and sizes of agility, but all of them are based on Goldman's model. Previous chart illustrates Sharifi \& Gang's methodology (2001) for achieving organizational agility which was also designed on Goldman's model.

\subsection{Goldman, Nagel, and Priess's Agile Model}

Goldman \& Nagel define agility as the usage of the combinations of new and modern productive technologies. Goldman et al. (1995) in their book entitled as "Agile Competitors and Virtual Organization" suggest that agility includes four interconnected principles: the enrichment of the customers, ability to control changes and uncertainty, coordination, and effective factor of people and information. (Figure 3).

\section{Agility Measurement via Fuzzy Logic}

\section{Step 1: Determine Agility Attributes}

The first task in successful analysis and organizational agility measurements is to define agility attributes (AA). Agility attributes in the current paper are directed originated from Goldman's model. In order to measure the amount of the agility, research literature is used. Table 1 lists the agile descriptions for measuring the agility index in the 
organization.

\section{Step 2: Design of Assessing Expressions and their Priority}

In this stage, the proper linguistic scales for determining performance rate and the importance of agility capabilities are determined and in most cases, it is impossible for specialists to determine the score of the ambiguous index. So, linguistic expressions are used to clarify performance classifications and importance of agility capabilities. (Lin \& et al, 206:358) (Table 4)

In order to prevent various arguments, linguistic expressions and equal MFS are used to study assessing expressions. Table 5 illustrates the linguistic variables and their corresponding numbers.

\section{Step 3: Assessing Criteria}

In this step, agility attributes are assessed through the linguistic expressions and the linguistic expressions are approximated by fuzzy numbers. Then, based on the corresponding relationship between the linguistic expressions and fuzzy numbers, the linguistic expressions are rated and the importance of fuzzy numbers is estimated.

\section{Step 4: Accumulation of Fuzzy Rating \& Weights in FAI}

Table 6 lists the average of fuzzy rates and fuzzy weights for the main criteria AAi and sub- criteria

Aaij. The Uniform fuzzy rating of the main criteria is accounted and the results are shown here:

$\begin{array}{lcc}\text { AA } 1=0.6605 & 0.7778 & 0.8847 \\ \text { AA2 }=0.5457 & 0.6830 & 0.8211 \\ \text { AA } 3=0.5313 & 0.6757 & 0.8167 \\ \text { AA } 4=0.6278 & 0.7519 & 0.8680\end{array}$

Fuzzy agility index (FAI)is accounted:

$\mathrm{FAI}=0.5958 \quad 0.7246 \quad 0.8489$

\section{Step 5: converting FAI to subtle Linguistic Expressions}

After we calculated FAI, it is time to determine agility level. So, those linguistic expressions which are equal or closer to FAI are estimated to get a natural expression for agility level series(AL). table 7 shows the selected ALs and their corresponding member functions.

Now the distance are formulated to use FAI members of A:

$\mathrm{d}(\mathrm{FAI}, \mathrm{DA})=0.890$

$\mathrm{d}(\mathrm{FAI}, \mathrm{EA})=0.1361$

$\mathrm{d}(\mathrm{FAI}, \mathrm{VA})=0.0564$

$\mathrm{d}(\mathrm{FAI}, \mathrm{HA})=0.2188$

$\mathrm{d}(\mathrm{FAI}, \mathrm{A})=0.3906$

$\mathrm{d}(\mathrm{FAI}, \mathrm{FR})=0.5632$

$\mathrm{d}(\mathrm{FAI}, \mathrm{SA})=1.2688$

$\mathrm{d}(\mathrm{FAI}, \mathrm{LA})=0.9092$

$\mathrm{d}(\mathrm{FAI}, \mathrm{S})=1.0$

Finally, in order to calculate the Euclid distance (d) between FAI to each member is used in AL series:

Therefore, if we compare the linguistic label with $\mathrm{d}$ minimum, Saipa Yadak Co. can be labeled as "very agile".(Figure4)

\section{Step 6: Rating Agile Sub- criteria}

Although the agile index of the organization is very close to "very agile", it is far away from "extremely agile". The rate of each sub criteria is calculated through its de- phasing and these rates show the effect of each sub criteria on providing the agility of the organization.(Table 8) It needs to be noted that all related calculations in fuzzy method are designed in MATLAB software by the researcher.

\section{Conclusion}

Complicated equations and rapid revolutions in industry and business in modern age from one hand and the governing conditions in local economical agencies and the importance of exports development and presence in the international competitions from the other hand, make us to look for several new strategies. In this regard, stepping 
toward agile agencies seems to be a modern and vital solution. IT which is considered as one of the most efficient technologies ever proposed is one of the most important elements for creating agility and according to its growth in field of production, it is impossible to gain it in the organization unless we implement it. Applying IT in these organizations changes the pyramid structure of the organizations into a flat format with the least costs and the highest assurance. Agile measurement not only estimates the amount of the agility in the organization, but it also helps the managers to recognize the strengths and weaknesses of their organizations to gain the required agile level. It is also useful in improving the quality for sorting the data and the vital quantitative factor make them to show their own problems and is more beneficial for unguided attempts (Henfer \& Grumman, 206:78). Fuzzy logic is the best solution for the problems and it is able to be applied both in small and simple microcontrollers and multi- channel computers, huge nets and controlling systems. Fuzzy logic can be used in hardware, software or a combination of both. It is an easy way to achieve certain results based on unclear and ambiguous data. The methodology of this logic for controlling the systems is similar to human's decision- making process, but it is faster and subtler. This model is experience- based and relies on the user's experience for technical understanding of the system.

According to the calculations which were based on the fuzzy method, the agility degree of Saipa Yadak Co. was estimated as "very agile", but it is far from "extremely agile".

Table 9 shows the calculated rates and the critical obstacles of this company for reaching the required agility level.

\section{The Critical Obstacles (findings)}

As it can be observed, the lowest $\backslash$ score in above table belongs to the sub criteria "the presence of the strategy of communicating with the customers" which is related to "the customer enrichment" criterion.

\section{Suggestions}

The findings of this research show that there are some obstacles on the way to achieve the required agility level, "extremely agile" in the organization. So, the researcher has prepared below suggestions to solve this problem:

1- The top managers need to design a perfect and clear strategy for their customers

2- A new and better program and system might be provided to deliver better services to the customers in proper time $\mathrm{m}$.

3- The organizational performance toward its customers needs to be measured systematically.

It may be concluded that these findings are specialized for Saipa Yadak Co. and hence, it is suggested to perform several similar surveys (agility assessment) in different organizations as well to highlight the possible obstacles and weaknesses and pave the way for achieving the optimum agility level.

\section{References}

Agarwal, Ashish, Shankar, Ravi, Tiwari, M.K. (2007). Modeling agility of supply chain, Management, Vol .36, P .443 -457.

Christopher, M. (2000). The agile supply chain, Industrial Market Manage, Vol.29, No.1, PP. 37-44.

Ferdows, K, De Meyer,A. (1990). Lasting hmprovements in manufacturing performance: in search of a new theory, Journal of Operations Management, Vol.9 No.2, pp.168-83.

Goldman, S, Nagel, R. (1995). Management,Technology and Agility:The Emergence of New Era in Manufacturing, International Journal of Technology Management, 8.35-18.(2/1).

Henfer, Rick \& Grumman, Northrop. (2006). Six sSigma Applied Throughout the lifecycle of an Automated Decision System, pp. 5-88.

jafarnejad, ahmad, shahaei,behnam. (2006). Introduction organization agility and agile manufacturing, 1Edition, Iran: mehraban nashr.

Katayama, H, Bennett, D. (1999). Agility,Adaptability and leanness:Acomparison of concepts and a study of practice, journal of production Economics,60D61,43-51.

Lin, Ching-Torng \& Chiu, Hero \& Chu,Po-Young. (2006). Agility index in the supply chain, Int. J. production Economics, Vol.100, No. 285-229.

Macaulay. J. (1996).Management in the agile organization,APQCquality press,Milwaukee,WI.

Mason-Jones, R, Towill,D. (1999). Total cycle time compression and the agilw supply chain,International Journal of production Economics, 62:61-73.

.Nagel, R.N, Dove. R. (1991). 21th centry manufacturing Enterprise strategy: An Industry Led view, Iccoca 
Institute,Lehigh University, Bethlehem .

Ramesh,g,.Devadasan,S. (2007). Literature Review on the Agile Manufacturing Crieria,Journal of Manufacturing Technology Management, Vol.18,No.2,p.p 182-201.

Sharifi, H; Zhang, Z. (1999). A methodology for achieving agility in manufacturing organization:Anintroduction, International Journal of Production Economics, Vol .62, P .7-22.2.

Van Hook, R, Harrision.A and Christopher, M. (2001). Meauring agile capabilities in the supply chain, International Journal of operations \&production Management, Vol. 21 No .1/2,2001,pp.126-147.

Vokurka.r,Fliedner,G. (1998). The jouney toward agility, Industrial Management \& Data Systems 98/4, pp.165-171.

Zadeh,L,A. (1973). Out line of a new approach to the analysis of complex system and design process, IEEE Transaction SME-3,Vol,1,pp:28-44.

Table 1.Description of Agility

\begin{tabular}{|l|l|}
\hline author & Agility \\
\hline 1.Goldman,Nagel\&Preiss.1995 & $\begin{array}{l}\text { To present value to customer, preparation to meet changes, notice to importance of skills and make } \\
\text { participation . }\end{array}$ \\
2.Vokurka\&Fliedner,1997 & Able to produce a lot of cheep and quality and present them in short time. \\
3.katayama\&bannett,1999 & Its relationship between organization and market in fact its base of competition . \\
4.christopher,2000 & When an organization can accelerate the quantity and variety of products. \\
5.Mason-jones,2000 & Usage of business knowledge and virtual organization of opportunities. \\
6.VanHook,Harrison\&Christopher,2001 & Reply to costumer business turbulence and gain necessary capabilities by thinking. \\
7.Itken,Christopher\&Towill,2002.7 & Able to recognize demand, fast reply, inflexibility and same time operation. \\
8.Stratton \&varburton,2003 & Creative products and unstable demands shows agility providing.
\end{tabular}

Table 2. Difference between traditional and agile organization(Ramesh \& davidsan,2007)

\begin{tabular}{|l|l|l|l|}
\hline Row & Criterion & Traditional organization & Agile organization \\
\hline 1 & Organizational structure & Vertical, tradition a liner & Plane, team, team working \\
\hline 2 & Investing & Inability & Autonomous and authorized \\
\hline 3 & Quality condition & Costumers satisfactory & Costumers satisfactory \\
\hline 4 & Personnel condition & week skills & Learning personnel \\
\hline 5 & Personnel participation & Little & Power Personnel \\
\hline 6 & Manage condition & Stagnant and dictator & Participate management \\
\hline 7 & Expense management & Traditional and very expensive & $\begin{array}{l}\text { On the basis of strategy, quality and } \\
\text { productivity }\end{array}$ \\
\hline 8 & Automation & Direct and fixed automation & Flexible and fast \\
\hline 9 & Technology in corporation & $\begin{array}{l}\text { Corporate technology of directly in current system } \\
\text { information }\end{array}$ & Incorporation of IT engineering \\
\hline 10 & Time management & Not effective & Very effective \\
\hline 11 & Product service circle & Long term and inflexible & Short term and flexible \\
\hline 12 & Out sourcing & Just through contract & Principle of supply management \\
\hline
\end{tabular}

Table 3. Differences of learning and traditional organization

\begin{tabular}{|l|l|l|}
\hline duties & Traditional organization & Learning organization \\
\hline $\begin{array}{l}\text { Determination path } \\
\text { general }\end{array}$ & $\begin{array}{l}\text { Great management can provide a perfect organizational } \\
\text { view }\end{array}$ & $\begin{array}{l}\text { There is a general view but management can improve is } \\
\text { surly }\end{array}$ \\
\hline $\begin{array}{l}\text { Arrange and execute } \\
\text { the rules }\end{array}$ & $\begin{array}{l}\text { Perfect management decide a bout kind of rules and } \\
\text { how to do these actions. }\end{array}$ & $\begin{array}{l}\text { Arrange all of personnel and general opinion in different } \\
\text { levels at organization }\end{array}$ \\
\hline $\begin{array}{l}\text { Nature of systematic } \\
\text { thinking }\end{array}$ & $\begin{array}{l}\text { Every body should be her/his job responsible and it } \\
\text { emphasis on personnel abilities }\end{array}$ & Employee understand their methods and others \\
\hline Remove the paradox & $\begin{array}{l}\text { It can be removed by authority and different levels } \\
\text { structure can be should by general cooperation and combination of } \\
\text { and }\end{array}$ & $\begin{array}{l}\text { A manager can create organizational view encourage } \\
\text { and punish correctly and control personnel actives }\end{array}$ \\
\hline $\begin{array}{l}\text { Strategy } \\
\text { motivation }\end{array}$ & $\begin{array}{l}\text { A manager should created general a view power the } \\
\text { personnel and encourage } \\
\text { management } \\
\text { effective }\end{array}$ \\
\hline
\end{tabular}


Table 4. Criterion agility index to assess agility index organization

\begin{tabular}{|c|c|c|c|}
\hline Symbol & Index & Index & Main criterion \\
\hline AA11 & Costumer communicational strategy & \multirow{5}{*}{ AA1 } & \multirow{5}{*}{ Customers satisfaction } \\
\hline AA12 & Manager should involve result of costumers services & & \\
\hline AA13 & Costumers opinions are important to design the products and services procedures. & & \\
\hline AA14 & Evaluation results with costumers systematically & & \\
\hline AA15 & Provide enough services at proper time & & \\
\hline AA21 & An organization should decide with consultant & \multirow{4}{*}{ AA2 } & \multirow{4}{*}{ Cooperation } \\
\hline AA22 & Provide the purposes and benefits of procedures in team working & & \\
\hline AA23 & Costumers can meet managers & & \\
\hline AA24 & Cooperation and communication organization & & \\
\hline AA31 & Organizational flexibility & \multirow{5}{*}{ AA3 } & \multirow[t]{5}{*}{ Control change } \\
\hline AA32 & Prepare to create organizational changes & & \\
\hline AA33 & Able to use new technologies to provide the services & & \\
\hline AA34 & Reengineering and restrict in organization again & & \\
\hline AA35 & Competency of personal to decide & & \\
\hline AA41 & Educate the personal to communication with cost timers effectively & \multirow{5}{*}{ AA4 } & \multirow{5}{*}{ Personal and information } \\
\hline AA42 & How they accept new technologies & & \\
\hline AA43 & Inter important information in web site & & \\
\hline AA44 & Provide electronic consulting to costumers & & \\
\hline AA45 & Fast provide services \&communication with other organizations & & \\
\hline
\end{tabular}

Table 5. Linguistic variables and similar numbers

\begin{tabular}{|llc|lcc|}
\hline Performing rank & & & Weight importance & \\
\hline Linguistic expression & symbol & fuzzy number & Linguistic expression & symbol & fuzzy number \\
\hline worst & $\mathrm{W}$ & $(0,0.05,0.15)$ & very low & VL & $(0,0.05,0.15)$ \\
very poor & $\mathrm{VP}$ & $(0.1,0.2,0.3)$ & low & $\mathrm{L}$ & $(0.1,0.2,0.3)$ \\
poor & $\mathrm{P}$ & $(0.2,0.35,0.5)$ & fairly low & FL & $(0.2,0.35,0.5)$ \\
fair & $\mathrm{F}$ & $(0.3,0.5,0.7)$ & medium & M & $(0.3,0.5,0.7)$ \\
good & $\mathrm{G}$ & $(0.5,0.65,0.8)$ & fair high & FH & $(0.5,0.65,0.8)$ \\
very Good & $\mathrm{VG}$ & $(0.7,0.8,0.9)$ & high & $\mathrm{H}$ & $(0.7,0.8,0.9)$ \\
Excellent & $\mathrm{E}$ & $(0.85,0.95,1.0)$ & very high & VH & $(0.85,0.95,1.0)$ \\
\hline
\end{tabular}

Table 6. Fuzzy average rating and weight of criterion and sub criterion

\begin{tabular}{|lccc|}
\hline AAi & AAij & \multicolumn{3}{c|}{ Fuzzy average rating } \\
\hline AA1 & & & $\mathbf{( 0 . 6 6 0 , 0 . 7 7 7 8 , 0 . 8 8 4})$ \\
AA11 & $0.7200,0.8300,0.9200$ & $0.8500,0.9500,1.0000$ & \\
AA12 & $0.6500,0.7700,0.880$ & $0.7100,0.8300,0.9200$ & \\
AA13 & $0.5400,0.6800,0.8200$ & $0.7600,0.8600,0.9400$ & \\
AA14 & $0.7300,0.8300,0.9200$ & $0.820,0.9200,0.9800$ & \\
AA15 & $0.6500,0.7700,0.8800$ & $0.8200,0.9200,0.9800$ & \\
AA2 & & & $\mathbf{( 0 . 5 4 5 7 , 0 . 6 8 3 0 , 0 . 8 2 1 1 )}$ \\
AA21 & $0.5400,0.6800,0.8200$ & $0.6200,0.7400,0.8600$ & \\
AA22 & $0.5000,0.6500,0.8000$ & $0.6600,0.7700,0.8800$ & \\
AA23 & $0.6600,0.770,0.8800$ & $0.7300,0.8300,0.9200$ & \\
AA24 & $0.4600,0.6200,0.7800$ & $0.5800,0.7100,0.8400$ & \\
AA3 & & & \\
AA31 & $0.5400,0.6800,0.8200$ & $0.7313, \mathbf{0 . 6 7 5 7 , 0 . 8 1 6 7 )}$ \\
AA32 & $0.4200,0.5900,0.7600$ & $0.6100,0.7400,0.8600$ & \\
AA33 & $0.5400,0.6800,0.820$ & $0.6100,0.7400,0.8600$ & \\
AA34 & $0.6100,0.7400,0.8600$ & $0.7300,0.8300,0.9200$ & \\
AA35 & $0.5300,0.6800,0.8200$ & $0.6500,0.7700,0.8800$ & \\
AA4 & & & $\mathbf{( 0 . 6 2 7 8 , 0 . 7 5 1 9 , 0 . 8 6 8 0 )}$ \\
AA41 & $0.6100,0.7400,0.860$ & $0.7500,0.8600,0.9400$ & \\
AA42 & $0.6500,0.7700,0.880$ & $0.7200,0.8300,0.9200$ & \\
AA43 & $0.6200,0.7400,0.860$ & $0.6900,0.8000,0.9000$ & \\
AA44 & $0.6100,0.7400,0.860$ & $0.7500,0.8600,0.9400$ & \\
AA45 & $0.6500,0.7700,0.880$ & $0.7200,0.8300,0.9200$ & \\
\hline
\end{tabular}


Table 7. Fuzzy variables and similar numbers to determine agility level (Lin\&etal,2006,296)

\begin{tabular}{|llc|}
\hline Symbol & linguistic variables & fuzzy number \\
\hline DA & Definitely Agile & $(0.8,0.9,1.0)$ \\
EA & Extremely Agile & $(0.7,0.8,0.9)$ \\
VA & Very Agile & $(0.6,0.7,0.8)$ \\
HA & Highly Agile & $(0.5,0.6,0.7)$ \\
A & Agile & $(0.4,0.5,0.6)$ \\
FR & Fairly & $(0.3,0.4,0.5)$ \\
SA & Slightly Agile & $(0.2,0.3,0.4)$ \\
LA & Lowly Agile & $(0.1,0.2,0.3)$ \\
S & Slowly & $(0.0,0.1,0.2)$ \\
\hline
\end{tabular}

Table 8. Rating of sub criterions

\begin{tabular}{|ll|}
\hline Rating & criterion \\
\hline 0.0651 & AA11 \\
0.1526 & AA12 \\
0.1526 & AA13 \\
0.0825 & AA14 \\
0.0768 & AA15 \\
0.187 & AA21 \\
0.1613 & AA22 \\
0.1429 & AA23 \\
0.1937 & AA24 \\
0.1461 & AA31 \\
0.1685 & AA32 \\
0.1685 & AA33 \\
0.1388 & AA34 \\
0.1685 & AA35 \\
0.1175 & AA41 \\
0.1175 & AA42 \\
0.1594 & AA43 \\
0.1175 & AA44 \\
0.1444 & AA45 \\
\hline
\end{tabular}

Table 9. results of research

\begin{tabular}{|l|l|l|}
\hline rating & criterion & Index \\
\hline 0.0651 & Costumer communicational strategy in organization & AA11 \\
\hline 0.0768 & Provide enough services at proper time & AA15 \\
\hline 0.0825 & Assessing performing results with costumers systematically & AA14 \\
\hline
\end{tabular}
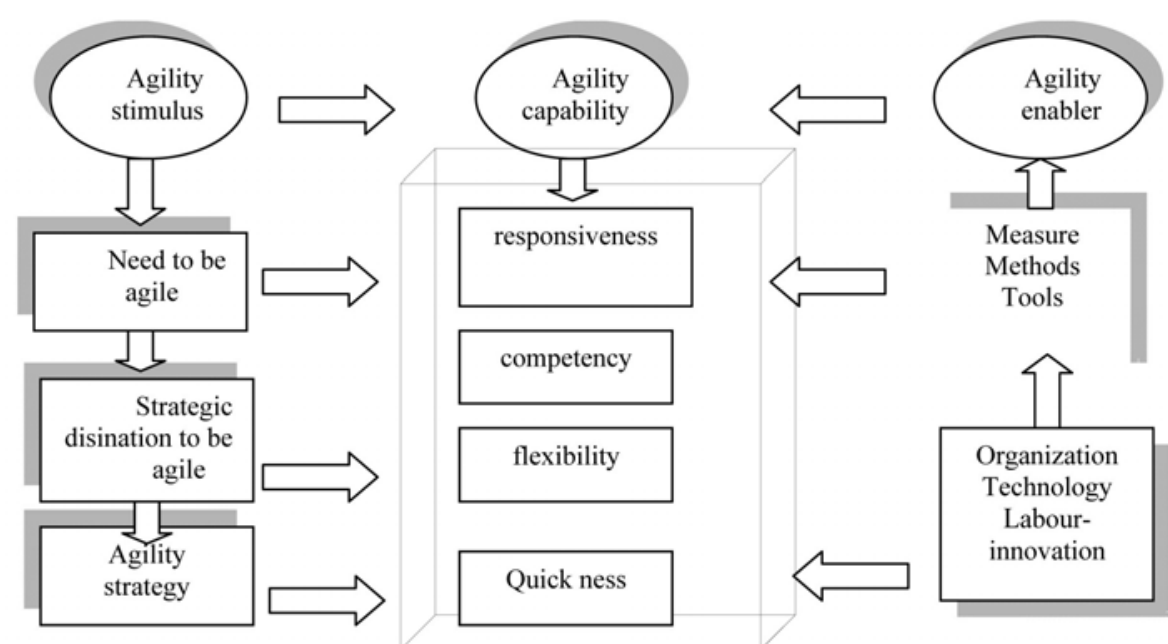

Figure 1. Model of conceptual agility (sharifi\&zhang,2001) 


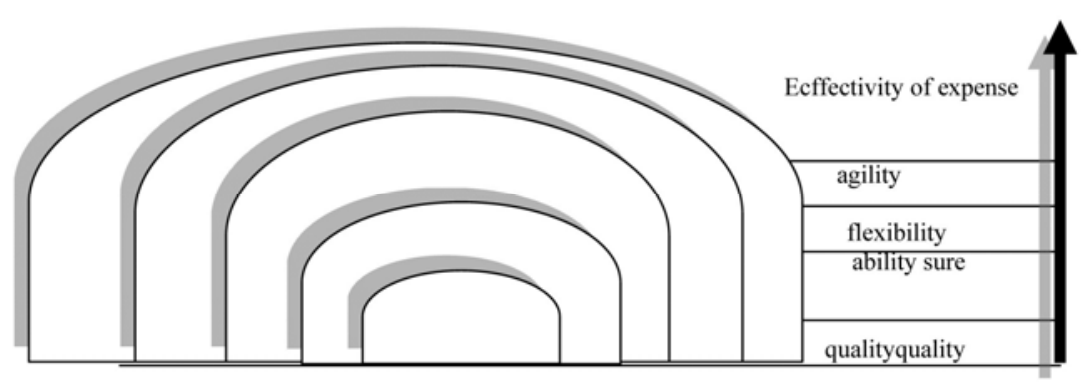

Figure 2. Improve agility capabilities(Ferdows\&Meyer,1990)

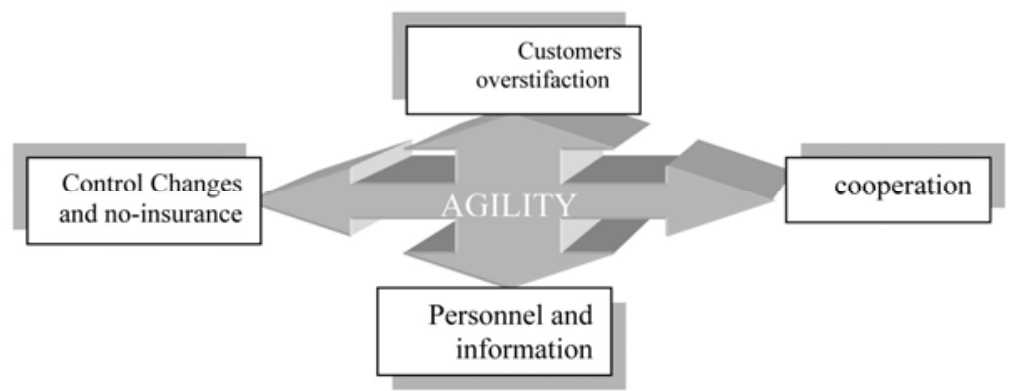

Figure 3. Agility model (Goldman\&Nagel,1995)

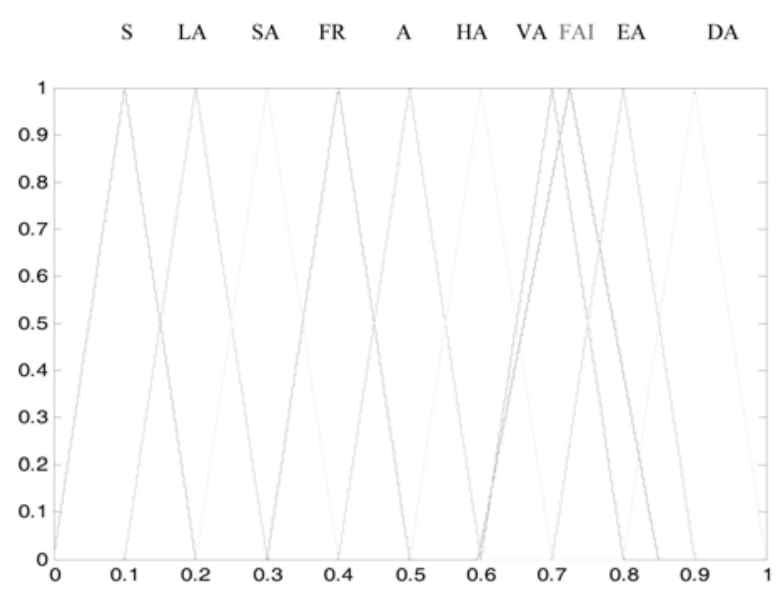

Figure 4. Fuzzy variables and similar numbers\& FAI 